\title{
Single-Photon Emission Computed Tomography in Neurotherapeutics
}

\author{
Michael D. Devous, Sr. \\ Nuclear Medicine Center and Department of Radiology, University of Texas Southwestern Medical Center, Dallas, \\ Texas 75390-9061
}

Summary: The measurement of regional cerebral blood flow (rCBF) by single-photon emission computed tomography (SPECT) is a powerful clinical and research tool. There are several clinical applications now documented, a substantial number under active investigation, and a larger number yet to be studied. Standards regarding patient imaging environment and image presentation are becoming established. This article reviews key aspects of SPECT functional brain imaging in clinical practice, with a particular emphasis on therapeutics, including 1) the quality of the tomographic device, 2) the radiopharmaceutical employed, 3) environmental conditions at the time of radiotracer administration, 4) characteristics of the subject, 5) the format used for image presentation, and 6) the essential components of image processing necessary to the achievement of high-quality SPECT brain images. Next, a brief description of relevant radiation safety issues is provided. Finally, applications in molecular imaging, especially in small animal imaging for research as well as drug discovery and development are discussed. The gamut of SPECT studies from currently routine clinical applications to molecular imaging offers a wonderful frontier for opportunities to employ functional brain imaging in neurotherapeutics. Key Words: SPECT, rCBF, molecular imaging, radiopharmaceuticals, instrumentation.

\section{INTRODUCTION}

The measurement of regional cerebral blood flow (rCBF) by single-photon emission computed tomography (SPECT) represents the most commonly available and widely applied functional brain imaging technique used in clinical practice. Several recent reviews describe the use of SPECT alone or in combination with PET and/or fMRI [functional magnetic resonance imaging (MRI)] in studies of human cognition, imaging of neuroreceptor systems, in aiding diagnosis or assessment of progression or treatment response in various psychiatric and neurologic disorders, in neuropharmacologic challenge studies and in the new field of molecular imaging, including imaging of transgene expression. ${ }^{1-11}$ Brain SPECT is now commonly used in diagnosis, prognosis assessment, evaluation of response to therapy, risk stratification, detection of benign or malignant viable tissue, and choice of medical or surgical therapy, especially in head

Address correspondence and reprint requests to Dr. Michael D. Devous Sr., Nuclear Medicine Center, University of Texas Southwestern Medical Center, 5323 Harry Hines Boulevard, Dallas, TX 753909061. E-mail: Michael.Devous@UTSouthwestern.edu. injury, ${ }^{3}$ malignant brain tumors, ${ }^{4}$ cerebrovascular disease, ${ }^{5}$ movement disorders, ${ }^{7}$ dementia, ${ }^{9}$ and epilepsy. ${ }^{11}$

Although PET provides the highest resolution functional brain images, ${ }^{6}$ SPECT images now have similar resolution (making any differences relatively inconsequential in clinical application), and ongoing developments in instrumentation are producing both SPECT and PET devices with $4 \mathrm{~mm}$ or better resolution. Also, although the breadth of radiopharmaceuticals available for brain SPECT is not as great as that for PET, ${ }^{6}$ the variety of SPECT tracers is expanding rapidly. It is noteworthy that SPECT perfusion tracers are Food and Drug Administration (FDA) approved and available for wide distribution, whereas FDA approval for nationally distributable PET tracers for brain function remains elusive. Although SPECT is limited by the lack of a direct measure of metabolism, cerebral perfusion and metabolism are tightly coupled under most normal and pathologic circumstances, limiting the clinical relevance of this limitation. Table 1 provides an overview of key features of SPECT, PET, and fMRI.

This article provides an overview of key aspects of SPECT functional brain imaging in clinical practice, with a particular emphasis on therapeutics. Because 
TABLE 1. Key Parameters of the Most Common Functional Brain Imaging Procedures

\begin{tabular}{llccc}
\hline Imaging Procedure & Parameter Measured & Spatial Resolution & Temporal Resolution & Test Environment \\
\hline PET $\left({ }^{18} \mathrm{FDG}\right)$ & $\mathrm{rCGM}$ & $4 \mathrm{~mm}$ & $30 \mathrm{~min}$ & Scan room \\
PET $\left(\mathrm{H}_{2} \mathrm{O}^{15}\right)$ & $\mathrm{rCBF}$ & $8 \mathrm{~mm}$ & $2 \mathrm{~min}$ & Scanner \\
SPECT $\left({ }^{99 \mathrm{~m}} \mathrm{Tc}\right)$ & $\mathrm{rCBF}$ & $7 \mathrm{~mm}$ & $20 \mathrm{sec}$ & Anywhere \\
SPECT $\left({ }^{133} \mathrm{Xe}\right)$ & $\mathrm{rCBF}$ & $12 \mathrm{~mm}$ & $2 \mathrm{~min}$ & Scanner \\
fMRI & $\propto \mathrm{rCBF}$ and rCBV & $3-8 \mathrm{~mm}$ & $100 \mathrm{msec}$ & Loud scanner \\
\hline
\end{tabular}

SPECT images of rCBF are influenced by a number of factors separate from pathology, we review herein the relevance of 1) the quality of the tomographic device, 2) the radiopharmaceutical employed, 3) environmental conditions at the time of radiotracer administration, 4) characteristics of the subject (e.g., age, gender, handedness, etc.), 5) the format used for image presentation, and we also provide 6) a brief overview of the essential components of image processing necessary to the achievement of high-quality SPECT brain images. For greater detail regarding image processing (e.g., filter choices, methods of reconstruction, attenuation, and scatter correction schemes, etc.), the reader is referred to available reviews. ${ }^{2,12}$ Next, a brief description of relevant radiation safety issues is provided. Finally, applications in molecular imaging, especially in small animal imaging for research as well as drug discovery and development are discussed. The reader is also referred to separate reviews in the present volume dedicated to head trauma, ${ }^{3}$ PET, ${ }^{6}$ movement disorders, ${ }^{7}$ Alzheimer's disease, ${ }^{9}$ advanced MRI techniques, ${ }^{10}$ epilepsy, ${ }^{11}$ multiple sclerosis, ${ }^{13}$ and small animal imaging, ${ }^{14}$ which contain information complementary to the present review.

\section{INSTRUMENTATION}

Tremendous growth in instrumentation over the last two decades has resulted in commercially available, very high-quality tomographs for SPECT brain imaging and very sophisticated image processing hardware and software. SPECT instruments developed by university-based research paved the way for current devices, but industry has led the computational hardware development process. SPECT instruments fall into two categories: non-camerabased and camera-based systems, although the latter dominate both academic and commercial development.

\section{Non-camera-based systems}

Non-camera-based systems include rotating detector arrays, multidetector scanners, and fixed rings and have all but disappeared from clinical use $\mathrm{e}^{2,12}$. The most widely available fixed-ring system is the CERASPECT,,${ }^{15}$ the first of the fixed sodium-iodide annulus/rotating collimator machines to come to commercial production. It yields 8to $10-\mathrm{mm}$ resolution images and is the only fixed-ring system still commercially available in the United States. This is a slice-based tomograph built with very thick crystals that operate much like pinhole cameras as they traverse through space to obtain tomographic data. Hill and colleagues ${ }^{16}$ have demonstrated that this device can image ${ }^{18} \mathrm{~F}$ in a single-photon (not PET) mode, as well as ${ }^{99 \mathrm{~m}} \mathrm{Tc}$ and ${ }^{123} \mathrm{I}$. In a recent reincarnation as the NeuroFOCUS system, it has demonstrated 3-mm spatial resolution with ${ }^{99 \mathrm{~m}} \mathrm{Tc}$-labeled rCBF tracers in man, the highest spatial resolution SPECT or PET system that is commercially available (FIG. 1). Whereas resolution is excellent, image quality requires further development.

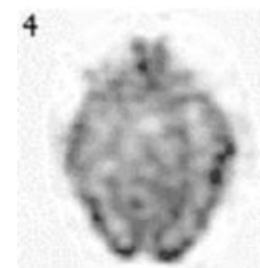

7

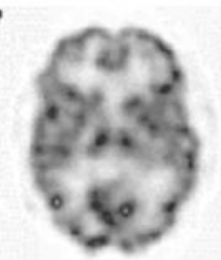

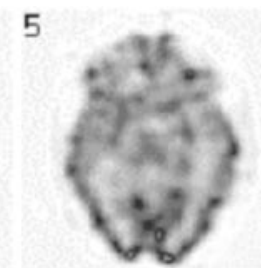

8

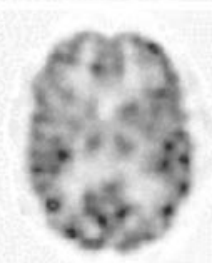

6

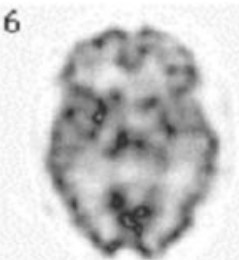

9

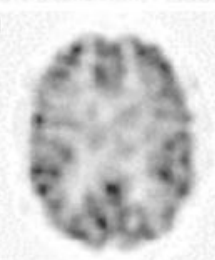

4

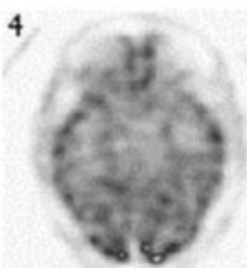

7

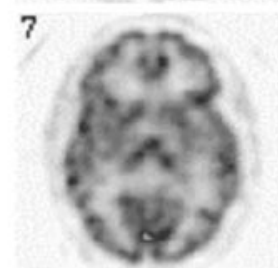

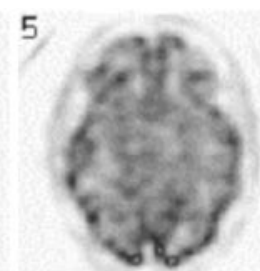

8

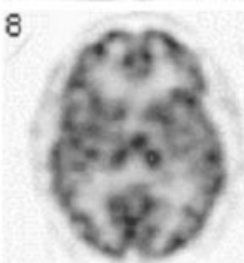

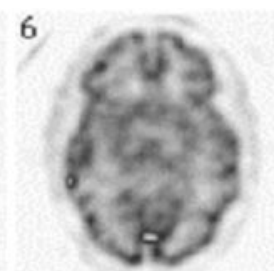

9

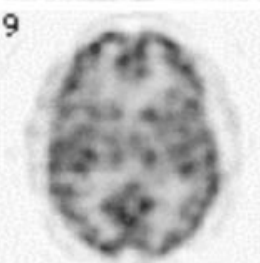

FIG. 1. High-resolution rCBF images obtained in two different patients with the NeuroFOCUS High-Definition Focusing Emission Tomographic Scanner (HDFET) using ${ }^{99 m}$ Tc HMPAO. (Images provided courtesy of NeuroPhysics Corp., Shirley, MA.). 


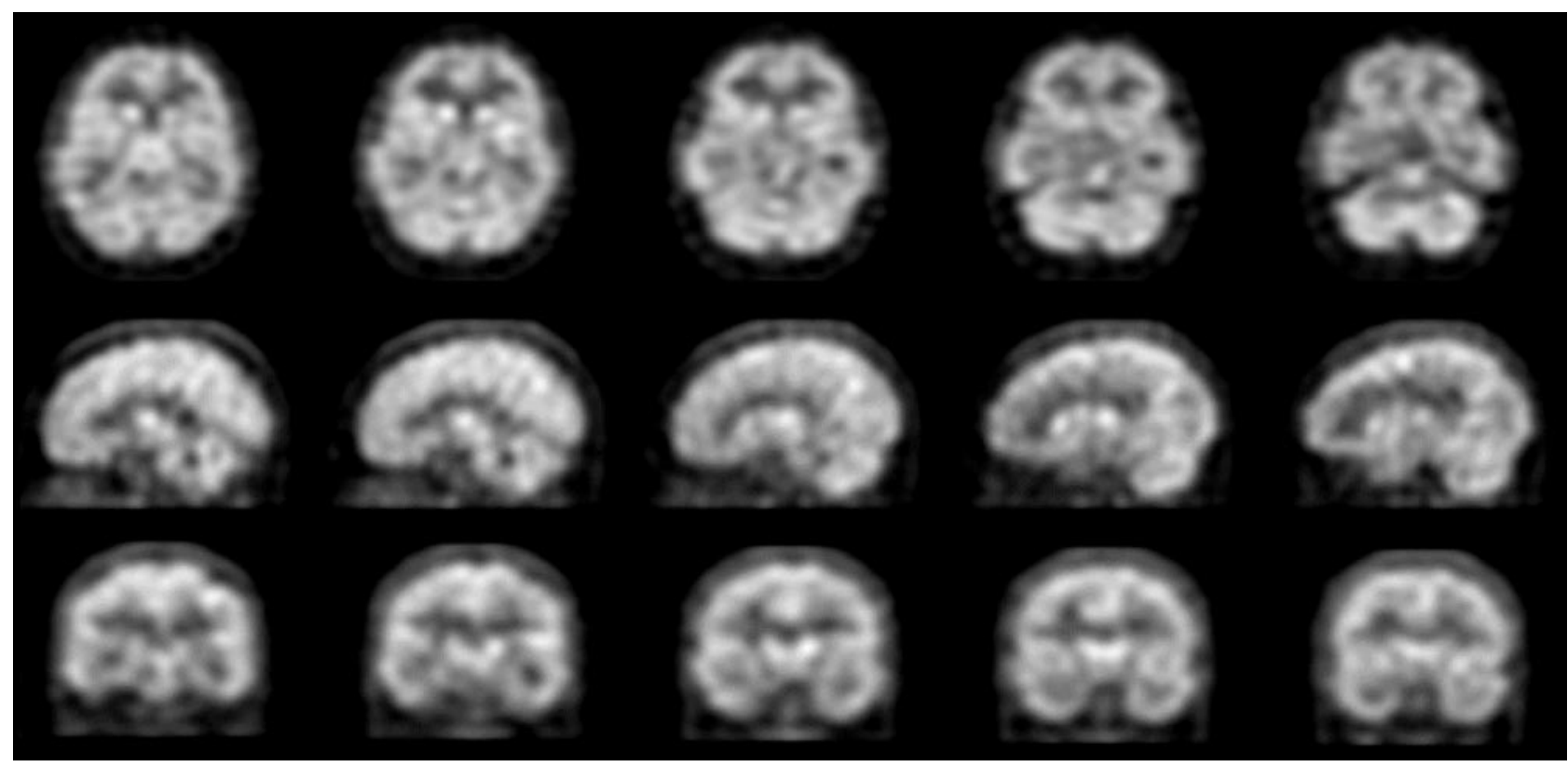

FIG. 2. Typical high-resolution rCBF SPECT images obtained using ${ }^{99 m} \mathrm{Tc}$ HMPAO and the PRISM $3000 \mathrm{~S}$ tomograph in a normal volunteer. Top panel shows transverse, middle panel shows sagittal, and bottom panel shows coronal images.

\section{$\gamma$-Camera-based systems}

Both single-head and multihead $\gamma$-camera-based systems are vastly more prevalent than dedicated tomographs, primarily because they can do both head and body SPECT. Most of these systems provide 7- to $10-\mathrm{mm}$ resolution images with static tracers. Unfortunately, single-head systems suffer from poor sensitivity and prolonged imaging times and so high-quality brain SPECT requires either dual- or triple-headed $\gamma$-cameras. A collaborative team from The University of Texas Southwestern Medical Center at Dallas and the nuclear engineering division of Technicare developed the first three-head $\gamma$-camera SPECT system to address the limited sensitivity of single-head systems. ${ }^{17}$ This system (PRISM) is capable of both head and body SPECT at high resolution with static tracers and with adequate sensitivity and rotation speed for dynamic tomography with ${ }^{133} \mathrm{Xe}$. The advantage of ${ }^{133} \mathrm{Xe}$ SPECT is that it yields absolute quantitation of $\mathrm{rCBF}(\mathrm{ml} / \mathrm{min} \cdot 100 \times g)$ without arterial blood sampling. ${ }^{18}$ Unfortunately, the high sensitivity that this technique requires limits spatial resolution (about $16 \mathrm{~mm}$ ). Three-head SPECT systems currently are the most sophisticated instruments for brain SPECT.

\section{Image processing essentials}

State-of-the-art SPECT systems can be expected to provide high resolution imaging of statically distributed brain radiopharmaceuticals with patient imaging times of 10-20 min (FIG. 2). All of the currently available threehead systems offer excellent spatial resolution: 6-mm resolution in the cortex and about $7 \mathrm{~mm}$ at the center of the brain, with appropriate collimators (e.g., ultra-high- resolution fan-beam collimators) and ${ }^{99 \mathrm{~m}} \mathrm{Tc}$ HMPAO (exametazime or Ceretec, Amersham/GE Healthcare, Princeton, NJ) or ${ }^{99 \mathrm{~m}} \mathrm{Tc}$ ECD (bicisate or Neurolite, DuPont, Billerica, MA).

To achieve such resolution, a few simple principles should be followed. First, it is necessary to reconstruct nearly motion-free data. A key instrumentation feature to facilitate collection of motion-free data are the capability of sequential image acquisition (e.g., collecting five 4-min studies to achieve a 20-min total acquisition time). Whereas a 20-min acquisition on a three-head system provides completely adequate data density, studies with less acquisition time may be acceptable for some clinical purposes. Data must then be filtered in three dimensions simultaneously. This can be accomplished by either filtering projection data before transverse reconstruction (which is automatically three-dimensional), or by filtering reconstructed data if the manufacturer offers true three-dimensional postfiltering. It is also important to use spatially invariant filters, such as Butterworth, exponential, or similar lowpass filters-optimizing cutoff frequency and order (slope) to maximize resolution while minimizing noise (graininess). Spatially varying filters (e.g., Metz or Weiner) can be used only if they are carefully calibrated for brain, which is seldom done.

Transverse reconstruction should be done at single pixel thickness so that later processing of oblique angle views (sagittal and coronal) will be unhindered by limited sampling errors. Furthermore, no filtering should be conducted during reconstruction as this is by definition a two-dimensional (within slice) filtering process ("no filtering" is often referred to as a "ramp reconstruction"). 
After reconstruction and filtering, the next step should be attenuation correction, where several basic principles need to be applied. First, use an attenuation correction coefficient that has been calibrated for your system. Second, ensure that the brain is aligned so that its long axis (anterior to posterior) is parallel to the long axis of the correction ellipse. Third, apply an ellipse shape that conforms to the changing shape of the skull (assuming that you use an approximation for attenuation correction such as the Chang method instead of a direct measurement). Thus, each transverse slice requires a unique ellipse (now an automated process on most systems that only takes a few seconds).

After reconstruction, filtering, and attenuation correction, the next step depends on the intended application. If the data are to be viewed for clinical interpretation, then the next step is to create oblique angle views. The brain has a complex and convoluted anatomy, and it is not possible to fully evaluate all components from a single (classically transverse) view. At a minimum, transverse, coronal and sagittal images should be created. Most modern software will allow you to orient brain to the canthomeatal line, or to some other angle such as might be used for CT or MRI, without prepositioning the subject to a specific anatomic orientation (see discussion below).

For most research purposes the reconstructed, filtered, attenuation-corrected image data are submitted to some analysis software, most of which depend on voxel-based statistics such as statistical parametric mapping (SPM). ${ }^{19}$ These analyses first morph image data into a common stereotaxic space, such as that of Talairach ${ }^{20}$ and apply sophisticated statistical tests to identify clusters of voxels that differ between groups, over the course of cognitive or pharmacologic challenges, or that distinguish a disease pattern from normal. In this regard, SPECT data are no different than PET data.

In summary, image processing software should support dynamic filtering, surface-variable attenuation correction, multiple angle (oblique) reconstructions, and three-dimensional as well as conventional cross-sectional displays. Although numerous permutations of reconstruction algorithms, filter choices, and attenuation methods can be pursued, the general guidelines offered above should result in optimal image generation.

\section{Dual-isotope imaging}

Dual-isotope imaging permits simultaneous imaging of ${ }^{99 \mathrm{~m}} \mathrm{Tc}$ and ${ }^{123} \mathrm{I}$ (or ${ }^{201} \mathrm{Tl}$ ) labeled brain radiopharmaceuticals administered to a single subject. Modern SPECT systems should have adequate energy resolution $(\leq 9 \%)$ and multiple-energy-window capability to separate ${ }^{99 \mathrm{~m}} \mathrm{Tc}$ and ${ }^{123} \mathrm{I}$ radiotracers in the same patient. We applied this technique to the simultaneous measurement of resting $\mathrm{rCBF}$ and changes induced by vasodilation (1 $\times g$ acetazolamide) in 10 subjects with cerebrovascular disease. ${ }^{21}$ Resting and vasodilated ${ }^{133} \mathrm{Xe}$ SPECT images were compared with resting $\left({ }^{99 \mathrm{~m}} \mathrm{Tc} \mathrm{HMPAO}\right)$ and postacetazolamide $\left[{ }^{123}\right.$ I IMP (iodoamphetamine) or HIPDM (trimethyliodobenzyl propanediamine)] dual-isotope images (FIG. 3). There was a linear relationship between ${ }^{133} \mathrm{Xe}$ SPECT and dual-isotope SPECT measurements of lesion/cerebellum ratios in baseline, vasodilated, and rest-minus-vasodilated data. A further advantage of the dual-isotope technique is that ${ }^{99 \mathrm{~m}} \mathrm{Tc}$ and ${ }^{123} \mathrm{I}$ images obtained through dual-isotope imaging are by definition in perfect anatomic registration. Additional applications for dual-isotope $\mathrm{rCBF}$ imaging include monitoring acute therapeutic interventions, single-session evaluations of cognitive or pharmaceutical challenge tests, and use in receptor modeling studies by directly measuring $\mathrm{rCBF}$ (normally deduced by assumption) with a ${ }^{99 \mathrm{~m}} \mathrm{Tc}$-labeled flow tracer, while simultaneously using an ${ }^{123}$ I-labeled receptor ligand.

\section{RADIOPHARMACEUTICALS}

Several ${ }^{99 \mathrm{~m}}$ Tc-labeled and ${ }^{123}$ I-labeled radiopharmaceuticals for the SPECT measurement of rCBF have been developed. It is also possible to measure regional cerebral blood volume (rCBV) using SPECT techniques. Receptor imaging with SPECT is still primarily a research tool, although at least one agent for D2 receptor studies $\left({ }^{123} \mathrm{I}\right.$ IBZM) and two agents for dopamine and serotonin transporter imaging ${ }^{123} \mathrm{I} \beta$-CIT and ${ }^{123} \mathrm{I}$ FPCIT) are commercially available in Europe. SPECT agents for dopaminergic, serotonergic, noradrenergic, cholinergic, and GABAergic receptor systems are in various stages of clinical trial or preclinical testing. At this moment, there is no tracer for the measurement of cerebral metabolism by SPECT. However, two metabolismrelated SPECT measurements can be made. The $\mathrm{rCBF} /$ rCBV ratio can be measured directly and is related to regional oxygen extraction. Also, several groups have tested a class of ${ }^{99 \mathrm{~m}} \mathrm{Tc}$ - and ${ }^{123} \mathrm{I}$-labeled agents that permit detection of hypoxic cerebral tissues.

\section{Diffusible tracers}

A diffusible tracer is one that passes through the circulation without engaging in metabolism or catabolism. Its concentration in tissue (brain) is therefore dependent only on the concentration gradient between arterial supply and tissue, and on the rate of delivery (perfusion). By measuring (directly or indirectly) the arterial concentration, usually known as the input function, and by imaging the rate of brain uptake and clearance, reasonably standard models of diffusible tracer clearance can be used to provide a quantitative measure of $\mathrm{rCBF}^{12,22}$ ${ }^{133} \mathrm{Xe}$ is the original noninvasive brain blood flow marker and has been in clinical use for several decades. 


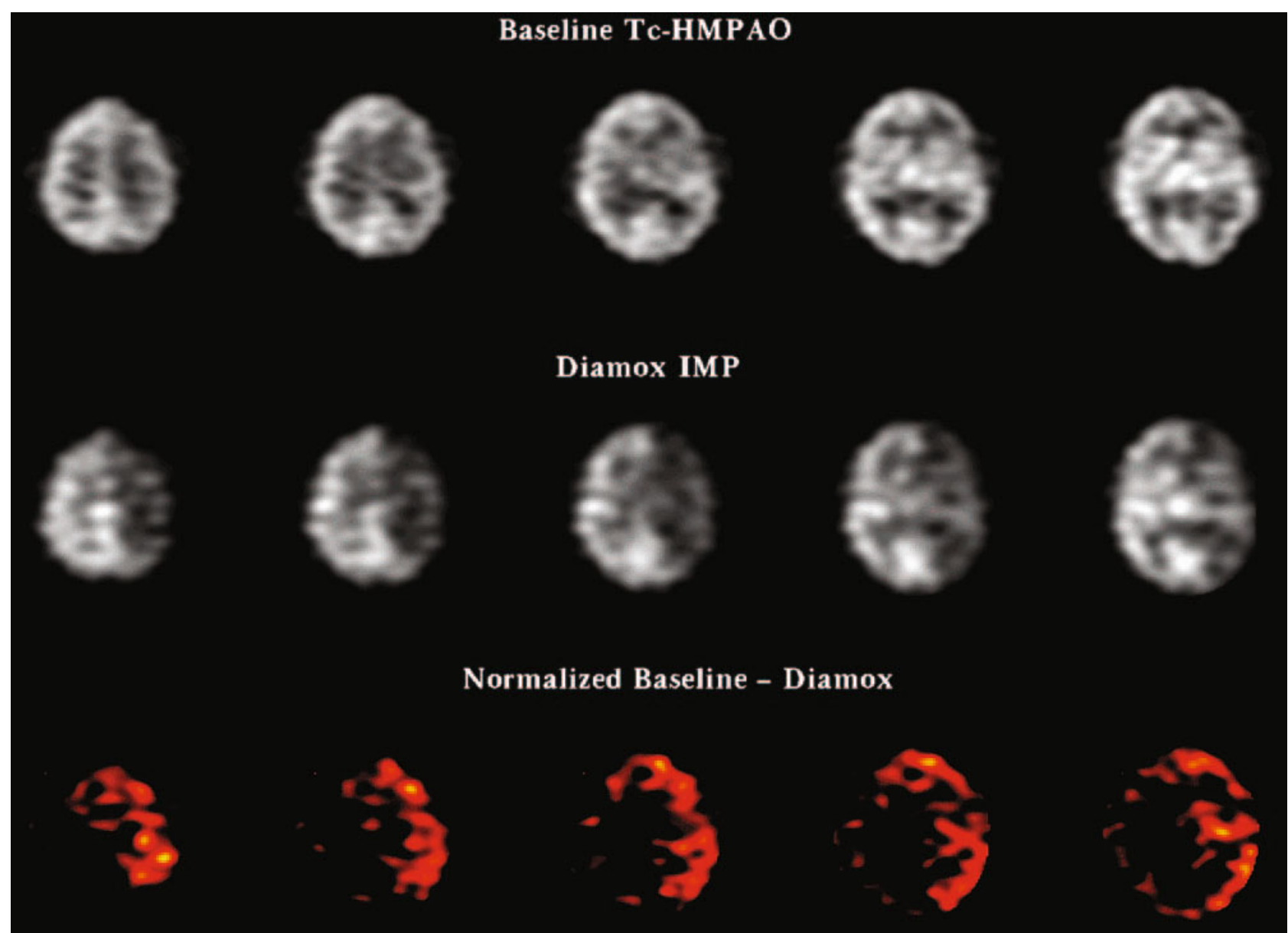

FIG. 3. Dual-isotope rCBF images in a patient with transient ischemic attacks demonstrating failed vasodilator reserve. Baseline study $\left({ }^{99 \mathrm{~m}} \mathrm{Tc}\right.$ HMPAO, top row) shows only mild left frontal hypoperfusion, whereas extensive reserve failure $\left({ }^{123} \mathrm{I} \mathrm{IMP}\right.$, middle row) is seen after vasodilation with acetazolamide (Diamox). The distribution of failed reserve is seen in the subtraction images (bottom row), which are easily obtained because the dual-isotope technique produces image sets that are in perfect anatomic registration.

Because ${ }^{133} \mathrm{Xe}$ has a short biological half-life, you can repeat examinations about every $15 \mathrm{~min}$, facilitating rest and stress brain imaging. In addition, the entire SPECT acquisition process is accomplished in $4 \mathrm{~min}$, an important feature for difficult, uncooperative patients.

\section{Static tracers}

All SPECT rCBF agents other than ${ }^{133} \mathrm{Xe}$ or ${ }^{127} \mathrm{Xe}$ (e.g., IMP, HIPDM, HMPAO, and ECD) were designed for use with rotating $\gamma$-cameras, which have low sensitivity. Consequently, rCBF tracers for use with such systems must be relatively stable in vivo (at least 60 min). Unlike the diffusible tracers, these radiopharmaceuticals are extracted by the brain on first arterial pass after intravenous injection and are then retained for several hours. Brain retention (or at least hindered diffusion from brain) is by some trapping mechanism, such as metabolic degradation or conformational alteration. Such agents are commonly referred to as "chemical microspheres." Stable distribution permits prolonged imaging times (as long as the patient doesn't move) so that specialized collimators can be used to produce high-resolu- tion images. Although count ratios among brain regions correctly represent relative $\mathrm{rCBF}$, most retention mechanisms do not lend themselves to simple mathematical models to provide absolute quantitation.

The first rCBF agent for use on rotating $\gamma$-cameras was ${ }^{123}$ I IMP, followed almost immediately by ${ }^{123}$ I HIPDM. IMP (Spectamine) was developed by Winchell et al. ${ }^{23}$ at MediPhysics, and HIPDM was developed by Kung et al. ${ }^{24}$ at SUNY. Both IMP and HIPDM follow higher cerebral blood flow levels more accurately than either HMPAO or ECD. Unfortunately, neither agent is commercially available in the United States, although IMP remains the most widely used rCBF tracer in Japan.

Investigators at Amersham ${ }^{25}$ and Volkert et al. ${ }^{26}$ at the University of Missouri developed the first of the technetium agents approved by the FDA for use in humans, ${ }^{99 \mathrm{~m}} \mathrm{Tc}$ HMPAO (Ceretec). ${ }^{99 \mathrm{~m}} \mathrm{Tc}-\mathrm{ECD}$ (Neurolite) is of a class suggested by Kung et al. ${ }^{27}$ and was developed and commercialized by DuPont. ${ }^{28}$ Both agents have good brain uptake and image defects similarly, although there are suggestions that during luxury perfusion following 


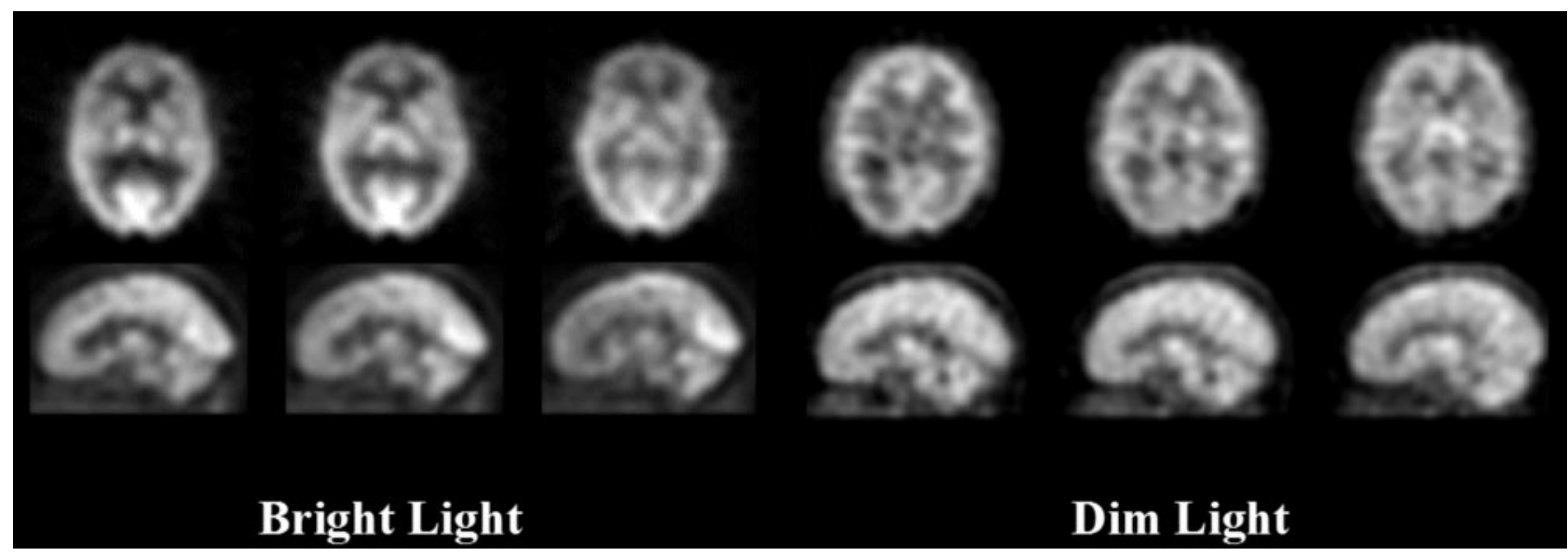

FIG. 4. Effect of visual stimulation on rCBF in normal volunteers. Left images were obtained from a subject during bright white light stimulation. Right images were obtained in a subject with eyes and ears open sitting in a dimly lit room. Note that perfusion decreases in the dim light condition relative to the bright light condition not only in primary visual cortex, but also in associative cortices.

stroke HMPAO will follow perfusion, whereas ECD will continue to show a defect at the site of injury. ECD clears from the blood and the body faster, consequently producing less radiation exposure per millicurie administered than HMPAO. In general, image contrast with ECD is superior to that with HMPAO, but recent studies with HMPAO obtained 90 min after injection demonstrate the potential for equivalent contrast (see FIG. 2). In separate studies in human subjects Devous and colleagues ${ }^{29,30}$ compared rCBF for either ${ }^{99 \mathrm{~m}} \mathrm{Tc}$ ECD or ${ }^{99 \mathrm{~m}} \mathrm{Tc}$ HMPAO to absolute rCBF.

\section{Receptor imaging}

There are currently no FDA-approved radiopharmaceuticals for neuroreceptor imaging in the United States, and its clinical role is not yet well established even in Europe and Japan where there are approved D2 and dopamine transporter tracers. However, early clinical trials and extensive PET experience suggest that SPECT imaging using specific receptor binding agents may soon find major clinical application. Most such agents rely on ${ }^{123} \mathrm{I}$ as the radiolabel, although a few ${ }^{99 \mathrm{~m}} \mathrm{Tc}$-labeled ligands are under investigation. ${ }^{31}$ Potential clinical applications for receptor imaging would include the diagnosis of specific neurodegenerative diseases, quantitative assessment of therapeutic interventions designed to alter receptor function, assessment of toxic effects of substances of abuse, and evaluation of interventions capable of producing prophylaxis. ${ }^{32}$ Areas for further investigation necessary to make receptor imaging a practical clinical tool include the establishment of correlations between the binding site concentration and the disease process, as well as the development of more accurate methods for absolute quantitation of the distribution of brain radioactivity. ${ }^{33}$ Combined use of receptor, perfusion, and structural imaging in a coregistration paradigm may also greatly enhance quantitation.

\section{Metabolism}

Metabolic aspects of neuronal function cannot be directly imaged with SPECT. We do not have, even on the horizon, an oxygen analog. Glucose metabolism has been monitored with great success by PET with ${ }^{18} \mathrm{FDG}$; it has been suggested that it might be possible to iodinate glucose analogs for SPECT that would behave like ${ }^{18}$ FDG. Although there have been two promising preliminary reports, neither has come to fruition at this time.

In summary, SPECT measures of $\mathrm{rCBF}$ are well developed, perhaps even better than for PET. Both dynamic and static techniques are effective. SPECT can also be used to image $\mathrm{rCBV}$, although clinical application of this technique has been minimal. There is great potential for receptor imaging, which has now moved out of the basic science laboratory and into clinical research. Interest in ${ }^{201} \mathrm{Tl}$ as a SPECT brain agent has also developed because it has been shown to be useful in distinguishing recurrent brain tumor from radiation necrosis after radiation therapy ${ }^{34}$ and in staging brain tumors. ${ }^{35}$ Lastly, progress is being made with glucose metabolic imaging at the animal level.

\section{FACTORS AFFECTING INTERPRETATION OF FUNCTIONAL BRAIN IMAGES}

\section{Environmental conditions}

Environmental conditions experienced by subjects during radiotracer administration can play a significant role in determining the observed $\mathrm{rCBF}$ distribution. The coupling of rCBF to regional metabolism has been frequently demonstrated under not only resting conditions, but also during cognitive or motoric activation. ${ }^{36-39}$ Thus, visual, auditory and somatosensory stimuli can all be expected to impact the regional level of neuronal activity and thus rCBF (FIG. 4). Although there are no clearly established standards describing the ideal condi- 


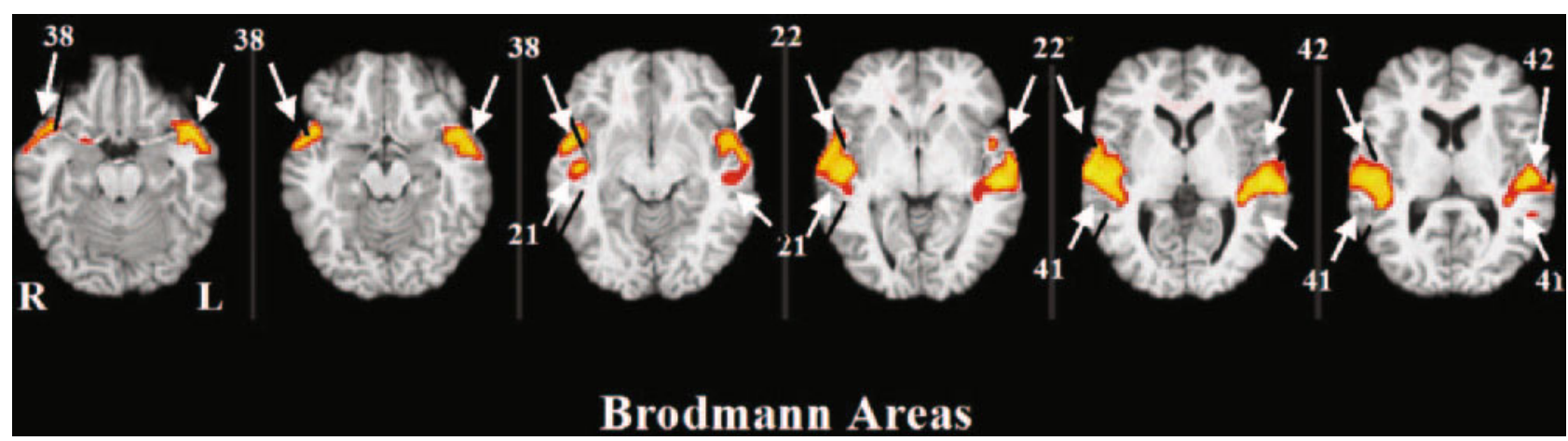

FIG. 5. Parametric images derived from an SPM analysis representing areas of significant response to auditory stimulation (red) in 7 normal controls overlaid on an MRI Talairach-based registration model and labeled according to the responding Brodmann areas. Images are arranged to correspond (from left to right) to Talairach levels ranging from $-16 \mathrm{~mm}$ to $+12 \mathrm{~mm}$ below/above the AC-PC line. Cognitive activation from speech perception results in mild contralateral rCBF asymmetry in primary auditory cortices and symmetric responses in associative cortices.

tions for these environmental parameters, most investigators use an "eyes and ears open" imaging environment in which subjects are seated during radiotracer injection. ${ }^{1,2,11}$ Room lights are often dimmed to provide a minimum and relatively standard visual stimulus.

The duration of steady-state conditions necessary to ensure minimal variability induced by environmental conditions is also not well established. To some degree, this is a radiotracer-dependent issue. For example, ${ }^{99 \mathrm{~m}} \mathrm{Tc}-\mathrm{HMPAO}$ has very rapid first pass extraction, whereas a component of ${ }^{123}$ IMP is retained by lung and likely affects brain tracer distribution for 5-10 min after injection. ${ }^{133} \mathrm{Xe}$ is a dynamic tracer that must be imaged during administration. In each case, the requirements vary for how long environmental conditions must be constant both before and after tracer administration. As a general rule, we require steady-state environmental conditions for 10 min before and after tracer administration for injectables. No requirement after administration is needed for ${ }^{133} \mathrm{Xe}$.

\section{Subject characteristics}

Age, gender, handedness, anxiety, time of day (diurnal variations), blood pressure, arterial carbon dioxide levels, cognitive involvement (attention), and other factors are subject-specific determinants of rCBF. Although it is clear that there are both age $\mathrm{e}^{40-43}$ and gender ${ }^{40,44,45}$ effects on whole brain blood flow, regional effects are somewhat less well characterized. Age/gender interactions are commonly observed; that is, age changes in rCBF differ by gender and vice versa. Pediatric studies are rare, but also support age and gender effects on both global and regional cerebral blood flow. ${ }^{46}$

\section{Challenge studies}

Pharmacologic challenges induce alterations in $\mathrm{rCBF}$, which can provide useful tools for the discrimination of disease or the elucidation of brain functions as well as conundrums for image interpretation. For example, acet- azolamide is a cerebral vasodilator commonly used in the determination of vasodilatory reserve (FIG. 3), a very valuable tool in assessing vascular risk factors in cerebrovascular disease. ${ }^{47,48}$ Caffeine, which may be present in subjects in various quantities, can lead to reductions in both global and regional $\mathrm{CBF}^{49}$ The impact of other pharmacologic factors (e.g., antidepressants, antiepileptics, etc.) is only just now being elucidated. It is advisable to eliminate all such complicating factors for as long as possible preceding a study.

Cognitive challenges are also sources of valuable discrimination and unwanted variability. For example, mild visual stimulation (dimly lit room) seems to minimize variability among normals relative to deprivation of visual stimuli. ${ }^{12}$ Auditory stimuli must similarly be carefully controlled. However, specific sensory stimuli can induce asymmetry (FIG. 5) and lead to activation of not only primary and associative sensory cortices, but even of remote cortical and subcortical sites. ${ }^{50,51}$ In general, consistency is the greatest asset. That is, study all subjects under as identical a set of conditions as possible.

\section{Image presentation for clinical interpretation}

Recent advances in image processing instrumentation and SPECT tomographs have afforded the opportunity to present image data in a wide variety of formats. In addition to conventional transverse cross-sectional images, sagittal, coronal, and other oblique angle reconstructions are readily produced by most computer systems. Experienced observers recognize that certain brain structures are more readily appreciated in nonconventional display orientations. For example, evaluation of the medial aspect of the orbital frontal cortex is more readily performed from sagittal cross-sections than from transverse. Evaluation of mesial temporal lobe hypoperfusion in epilepsy is easiest in special oblique views designed to highlight the mesial temporal wall than in classic coro- 
TABLE 2. Brain SPECT_Imaging Principles

\begin{tabular}{|c|c|c|}
\hline \multirow{2}{*}{$\frac{\text { Topic }}{\text { Patient preparation }}$} & \multicolumn{2}{|c|}{ Key Factors } \\
\hline & $\begin{array}{l}\text { Quiet reproducible environment-eyes/ears } \\
\text { open; dimly lit room }\end{array}$ & $\begin{array}{l}\text { Intravenous line placed } \sim 10 \text { min before } \\
\text { injection-quiet } \sim 10 \text { min after injection }\end{array}$ \\
\hline \multirow[t]{3}{*}{ Radiopharmaceuticals } & $\mathrm{rCBF}$ tracers & Delay imaging for best results \\
\hline & ${ }^{99 \mathrm{~m}}$ Tc HMPAO Ceretec (Amersham) & 90 min for Ceretec \\
\hline & ${ }^{99 m}$ Tc ECD Neurolite (DuPont) & 45 min for Neurolite \\
\hline \multirow[t]{3}{*}{ Image acquisition } & High-resolution collimators & $\begin{array}{l}\text { UHR and Fan Beam when possible } \\
\text { Minimum radius (heads in close) }\end{array}$ \\
\hline & "Motion-free" positioning & Patient comfort first \\
\hline & & Multiple sequential acquisitions \\
\hline \multirow[t]{4}{*}{ Image processing } & Single-pixel reconstruction & No filtering during reconstruction \\
\hline & & Three-dimensional lowpass filtering \\
\hline & Attenuation correction & Shape conforming ellipse \\
\hline & Oblique reformatting & Transverse, sagittal, coronal, special views \\
\hline
\end{tabular}

nal, sagittal, or transverse views. It is wise to review studies in at least three orthogonal orientations.

Parametric image displays are moving from the realm of research applications to clinical utility. There is widespread use of both two- and three-dimensional displays to provide an anatomical reference (SPECT, PET, or MRI image) on which to display the results of a statistical analysis (FIG. 5). Although this is commonplace in research applications, the use of statistical renderings of any kind in clinical applications has been minimal (in sharp contrast with cardiac SPECT). This has been, in part, caused by the complexity of statistical analyses for functional brain imaging. Two recent innovations have altered this landscape at least in part. SPM had become so widespread in its utility, and so well validated, that some degree of automation is now possible. Certainly the first step in such an approach, image registration or image fusion, has indeed become automated and widely available on commercial SPECT systems. Furthermore, the Brain Imaging Council of the Society of Nuclear Medicine has established a freely available database of normal SPECT brain images (http://brainscans.indd.org/ brncncl4.htm). It is hoped that the combination of automated software and a large database will lead to statistical assistance in the interpretation of SPECT brain images as has occurred with the "bull's-eye" and other cardiac analyses.

Six conclusions can be drawn regarding image presentation. 1) SPECT rCBF studies should be presented in at least transverse, coronal, and sagittal cross-sections. 2) The conditions under which subjects are studied should be established as a laboratory standard and maintained for all studies. The most common standard is eyes and ears open in a dimly lit environment with minimal auditory "white noise." 3) The normal distribution of rCBF in such a setting shows symmetric flow distribution between homologous regions. 4) Both age and gender effects can be noted. They are only well characterized for whole-brain blood flow, which is not readily measured by conventional SPECT techniques. 5) Among brain stress tests that could be employed to enhance discrimination of disease, the only well-established technique is the acetazolamide vasodilator test. Under most circumstances, it reveals striking asymmetries in disease states of vascular origin. 6) Future research should focus on the establishment of statistical techniques and normative databases, and on the effect of environmental variations on regional cerebral blood flow. These key factors are summarized in Table 2. In addition, patient preparation, image acquisition, and related topics are described in the 1999 Procedure Guidelines Manual of the Society of Nuclear Medicine. ${ }^{52}$

\section{RADIATION RISK ISSUES}

There exists a general view that radiation is harmful at any level, and that consequently medical imaging procedures that involve exposure to any radiation whatsoever are associated with some level of risk. ${ }^{53}$ Great efforts (and costs) are extended to minimize radiation exposure for patients, research volunteers, and workers. With the advent of functional measures based on MRI imaging sequences, it is sometimes put forward that these techniques should be used in favor of PET or SPECT imaging whenever possible to avoid the perceived radiation risk of the radioactive tracer techniques. Much of this impression has been fostered by the widespread regulatory use of the "Linear No-Threshold Theory" regarding the assessment of radiation risk. ${ }^{54}$ The purpose of this section is to briefly describe the data regarding low-level radiation and risk and to clarify that in fact SPECT and PET procedures have no more risk than MRI-based procedures.

The "Linear No-Threshold Theory" assumes that measures of mortality, disease induction, or tissue injury caused by very high radiation exposure levels either in 
(e.g., nuclear accidents, atomic bomb exposures, or radiation therapy) can be extrapolated over many orders of magnitude to the much lower levels of radiation exposure incurred in diagnostic imaging procedures by a simple linear interpolation. However, most data indicate that this is not the case, but actually that risk asymptotes to zero at radiation exposure levels well above those incurred in diagnostic procedures for both adults and children. $^{55,56}$

In 1996, the Health Physics Society ${ }^{57}$ issued a policy statement indicating that, although there is substantial and convincing scientific evidence for health risk at high dose, for exposures below 10 rem "health risks are either too small to be observed or are nonexistent." The whole body dose of a typical SPECT brain imaging procedure is about $0.1 \mathrm{rem}$. In its assessment of risk to children for diagnostic imaging procedures used in clinical and research investigations, the Office of the Clinical Director of the National Institutes of Health stated: "The risk of increased rates of cancer after low-level radiation exposure is not supported by population studies of health hazards from exposure to background radiation, radon in homes, radiation in the workplace or radiotherapy. Compared to the frequency of daily spontaneous genetic mutations, the biologic effect of low-level radiation at the cellular level seems extremely low. Furthermore, the potentiation of cellular repair mechanisms by low-level radiation may result in protective effect from subsequent high-level radiation." 58 They concluded their risk review by saying: "Health risks from low-level radiation could not be detected above the 'noise' of adverse events of everyday life. In addition, no data were found that demonstrated higher risks with younger age at low-level radiation exposure."

Indeed, there are no data demonstrating harm to humans by radiation exposure at diagnostic imaging levels. In fact, current data support the presence of radiation hormesis: that low levels of radiation exposure induce beneficial effects of cellular repair and immune system enhancement. ${ }^{59}$ Therefore, it should be concluded that neither PET nor SPECT brain imaging procedures are associated with any particular risk over activities of daily living and certainly should not be considered to be any more risky than MRI or any of its associated functional imaging derivatives.

\section{MOLECULAR IMAGING}

There is a tremendous excitement surrounding opportunities to enhance patient care through molecular imaging. Molecular imaging's primary goal is the in vivo noninvasive localization and quantification of molecular processes (e.g., endogenous or exogenous gene expression, signal transduction, protein-protein interaction, and transcriptional regulation). The ability to monitor intra- cellular events in vivo provides important opportunities for basic researchers and clinicians. The main advantage of molecular imaging is the ability to study cellular events in real-time and in their in vivo context. Because noninvasive imaging allows repeated analyses of animals, such experiments provide highly valuable longitudinal data. The breadth of substrates accessible by molecular imaging is illustrated in FIG. 6.

Clinically, imaging of gene expression will be critical in the pharmacogenomic classification of disease and could reduce the need for invasive procedures such as explorative surgery and biopsy sampling and increase efficiency and speed of diagnostic testing. Moreover, as rationally designed and target-specific pharmaceutical agents are developed, noninvasive monitoring of genomic activity could provide early signs of patient response to treatment. Thus, molecular imaging holds promise to provide key insights into the molecular pathology of animal models of human diseases, to enhance the development of new molecular-targeted drugs, and to assist in the design and implementation of improved patient-tailored therapies. $^{60}$

Overall, the point is to quantitatively image reporter gene expression, and thereby infer levels, location, and duration of therapeutic gene expression. ${ }^{61}$ Although great progress has been made in the imaging of molecular process in oncology and other areas in small animal systems, this has proved more difficult in neuroscience. The principle impediment has, of course, been caused by the challenges of getting the appropriate vectors/probes across the blood-brain barrier. Several groups are, however, now making progress in creating blood-brain barrier-permeable probes. ${ }^{62}$

At the human level, molecular imaging of the CNS with SPECT has exclusively focused on neurotransmitter related measures. However, small animal imaging with SPECT is opening the door to examine many more aspects of molecular processes - which hopefully will translate into human imaging directly. In fact, molecular imaging of small laboratory animals, such as mice and rats, is currently a vital tool in the study of disease. Mouse models of human diseases, such as Parkinson's disease and Alzheimer's disease, provide important clues to the causes, diagnosis and treatment of such disorders. Ultra-high-resolution PET and SPECT devices constructed specifically for small animal imaging have enabled the visualization of biochemical processes in vivo in small animals. ${ }^{63}$ Small animal imaging, using PET or SPECT, offers the exciting possibility of studying the longitudinal behavior of a radiolabeled drug in vivo, allowing longitudinal experiments to assess the effects of therapy or competing drugs. To investigate multiple molecular events with PET, molecular probes are usually injected separately, allowing for the decay of one isotope before administration of the other. However, with 


\section{Examples of Existing Imaging Targets/Probes}

- Proteases: cathepsin B, cathepsin D, cathepsin $\mathrm{K}$, matrix metalloproteinase (MMP)1,MMP2,MMP7, cytomegalovirus protease, human immunodeficiency virus protease, herpes simplex virus protease, hepatitis $C$ virus protease, caspase-1, caspase- 3 and thrombin

- Receptors: somatostatin, bombesin, dopamine D2 and D1, serotonin, benzodiazepine, opioid, acetylcholine, adrenoceptor, oestrogen, cholecystokinin, epidermal growth factor receptor, vascular endothelial growth factor receptor (VEGFR), glycoprotein $\mathrm{Ib} / \mathrm{IIIa}$, folate, insulin, neurokinin, transforming growth factor, asialoglycoprotein and adenosine 2

- Enzymes: herpes simplex virus thymidine kinase, farnesyl transferase, toposiomerase, cytochrome $\mathrm{p} 450$, hexokinase, 3hydroxyacyl-coenzymeA dehydrogenase (HAD), choline metabolism, citrate metabolism, protein synthesis (amino acids), Akt kinase, $\beta$-galactosidase and glutamate carboxipeptidase

- Angiogenesis: E-selectin, $\alpha v \beta 3$,VEGFR, human vascular cell adhesion molecule 1, endoglin (CD105), thrombin and endostatin

- Apoptosis: annexin-V, caspase-3, PtdS-binding protein, synaptotagmin and tumour necrosis factor-related apoptosisinducing ligand

- Cellular tracking: CD8, CD4, CD34, neural progenitor cells, stem cells, macrophages, dendritic cells and tumor cells

FIG. 6. An illustration of the extent of targets and relevant substrates now accessible through molecular imaging. Though an extensive list, this represents only a subset of potential molecular imaging tools.

SPECT, one can perform simultaneous detection of multiple events by using multiple isotopes with different energy-rays.

Imaging studies in mice and other small animals are also challenged to obtain spatial resolution appropriate to the size of the organ of interest (e.g., a mouse brain is less than $1 \mathrm{~cm}$ across). ${ }^{64}$ Small animal PET systems have been designed with smaller, higher resolution detection elements, ${ }^{65}$, although the unknown motion of the positron before annihilation limits the resolution possible with PET (typically 1-2 $\mathrm{mm}$ ). In contrast, the resolution limitations of SPECT are almost entirely because of the geometric effects of the collimator, and in theory SPECT can provide much better resolution than PET for small animals. This is generally done by using specialized pinhole collimators, ${ }^{63}$ readily achieving $<1 \mathrm{~mm}$ spatial resolution, though with substantially poorer sensitivity than PET. However, there are a number of issues related to the physics of pinhole imaging which can degrade the resolution. One group ${ }^{66}$ has developed a multi-pinhole approach applied to a standard triple-head $\gamma$-camera that provided a system resolution of $2.0 \mathrm{~mm}$ with mean system sensitivity ranges from 330 counts per second (cps)/ megabecquerels (MBq) to $707 \mathrm{cps} / \mathrm{MBq}$. For comparison, a clinical SPECT system equipped with highresolution, parallel-hole collimators would provide a sensitivity of about $100 \mathrm{cps} / \mathrm{MBq}$ and a resolution of 7-9 $\mathrm{mm}$. Even higher resolutions $(200 \mu \mathrm{m})$ are possible with micropinhole apertures and ${ }^{125}$ I SPECT imaging. ${ }^{67}$ The first quantitative study of dopamine transporter (DAT) 
binding sites in the mouse brain using an ultra-highresolution pinhole SPECT system, was published recently. ${ }^{68}$ There was an excellent correlation between the quantitative SPECT imaging data and post mortem biodistribution analysis, and the test-retest variance was only $2.6 \%$. This is particularly encouraging for the performance of longitudinal studies in small animals focused on measuring small changes in brain function.

Until the present, molecular imaging has been largely confined to detection of proteins and reporter constructs. Detection of proteins as a general tool is problematic because of the need to develop suitable ligands on a case by case basis, a challenge at least as great as that for therapeutic drug development. Although reporter genes are of considerable value, the need for engineered cell lines and animals is an obstacle for widespread use. Thus, the development of broadly applicable methods to detect endogenous gene expression would be of significant interest.

On the gene therapy front, PET and SPECT have been used for imaging the distribution of a radiolabeled vector, immune cell trafficking, and assessment of transgene expression using diverse reporter genes and reporter probes. A reporter gene can be introduced into the target tissue by various methods (e.g., viral and nonviral delivery vectors). If the promoter leads to transcription of the reporter gene, then translation of the imaging reporter gene mRNA leads to a protein product that can interact with the imaging reporter probe. This interaction may be based on intracellular enzymatic conversion of the reporter probe with retention of the metabolite(s), or a receptor-ligand-based interaction. These in vivo molecular imaging technologies have been applied for gene therapy of cancer, cardiovascular, neurological, musculoskeletal, hepatic, and inherited diseases. ${ }^{69}$

Labeling of oligonucleotides for pharmacoimaging is one of the next substantial challenges for molecular imaging. Because of their excellent targeting capacities and ease of synthesis in high diversity, oligonucleotides are extensively used in vitro as ligands for nucleic acids (antisense oligonucleotides), proteins and small molecules (aptamer oligonucleotides). However, applications of oligonucleotides in vivo are still in their infancy and much work is needed to develop these compounds as pharmaceuticals. ${ }^{70}$ Several methods to label oligonucleotides with radioactive isotopes for imaging studies have been described, both with $\gamma$ emitters and with positron emitters. $^{71}$

\section{DRUG DISCOVERY AND DEVELOPMENT}

Molecular imaging with SPECT can play a substantial role in drug discovery and development. It is now possible to follow a specific molecular target in a live animal, follow a drug's distribution in the same animal, and quantitate the drug's direct effect on the target in live time. Small animal imaging systems are generally cheaper than their clinical counterparts and can be housed in basic science laboratories. ${ }^{72}$ Given the increasingly common use of mouse models of disease to validate potential drug targets, to assess therapeutic efficacy and to identify and validate biomarkers of drug efficacy and/or safety, the ability to image mouse models noninvasively has far-reaching applications in drug discovery and development. ${ }^{73}$

One major role is providing neuroreceptor occupancy studies that enhance our understanding of drug action in psychiatric illness. ${ }^{74}$ For example, all effective antipsychotics have significant D2 receptor occupancy. However, there is no clear relationship between occupancy and clinical response and the mechanisms underlying antipsychotic efficacy and the minimal effective D2 occupancy remain to be elucidated. Similarly, for SSRIs (selective serotonin reuptake inhibitors) high occupancies at the serotonin transporter (SERT) are achieved at therapeutic doses, although the minimum SERT occupancy required for therapeutic response remains undefined. In contrast, for benzodiazepines, clinical doses would appear to leave a wide margin of unoccupied receptors. Thus, in therapeutic drug development, SPECT neurotransmitter imaging techniques may be used to assess receptor occupancy profiles, likely drug dosages and dosing intervals that cannot be reliably assessed in humans by other methods.

Radiotracer imaging is being more frequently used by pharmaceutical companies to assess the pharmacokinetic and pharmacodynamic properties of candidate compounds in not only in animals but also in humans in phase I and phase II trials. Because of the greater availability of dopaminergic and serotonergic ligands for human imaging, such studies are particularly suitable in the development of putative antipsychotic and antidepressant drugs with affinity for D1 and D2 receptors, the DAT, 5-HT1A and 5-HT2A receptors, and the SERT. ${ }^{75}$ These studies are usually guided by prior results of in vitro radiolabeling studies and can provide insight as to the receptors to which the new compound may be expected to bind in humans in vivo.

Certainly SPECT (and PET) has a clear advantage over magnetic resonance-based techniques in terms of sensitivity. For example, whereas magnetic resonance spectroscopy (MRS) can only observe compounds present in at least micromolar $\left(10^{-6}\right)$ quantities, PET and SPECT can measure brain receptors present in nanomolar $\left(10^{-9}\right)$ to picomolar $\left(10^{-12}\right)$ range of concentrations. Moreover, in humans, the tracers themselves are usually administered in minute amounts (typical mass dose is less than $10 \mathrm{mg}$ ) and occupy only about $5 \%$ of available receptors. Because of this, pharmacological effects (including adverse effects) of the tracers are not generally 
seen. If molecular imaging is to be accepted as a reasonable source of surrogate markers in preclinical and clinical studies, the high sensitivity (and concomitant lack of pharmacologic effects) for the associated tracers ligands is essential.

\section{CONCLUSIONS}

SPECT functional brain imaging is a powerful clinical and research tool. There are several clinical applications now documented, a substantial number under active investigation, and an even larger number yet to be studied. Instrumentation continues to improve, although current SPECT tomographs yield excellent image quality. There is a rapidly expanding armamentarium of radiopharmaceuticals. Challenge tests, only well developed in cerebrovascular disease (the acetazolamide test for vasodilatory reserve), offer great promise in elucidating the extent and nature of disease, as well as predicting therapeutic responses. Some standards regarding patient imaging environment and image presentation are emerging. However, much is yet to be learned about the ideal circumstances for the performance and evaluation of SPECT functional brain imaging. Finally, molecular imaging offers an enormous frontier for additional opportunities to employ SPECT brain imaging in neurotherapeutics.

\section{REFERENCES}

1. Catafau AM. Brain SPECT in clinical practice. Part I: perfusion. J Nucl Med 42:259-271, 2001.

2. Devous MD Sr. SPECT functional brain imaging. In: Brain mapping: the methods (Mazziotta JC, Toga AW, eds), Ed 2, pp 513533. San Diego: Academic Press, 2002.

3. Lee B, Newberg A. Neuroimaging in traumatic brain imaging. NeuroRx 2:372-383, 2005.

4. Bonte FJ, Devous MD. SPECT brain imaging. In: Diagnostic nuclear medicine (Sandler MP, Coleman RE, Patton JA, Wackers FJTh, Gottschalk A, eds), Ed 4, pp 757-782. Philadelphia: Lippincott Williams and Wilkins, 2003.

5. Devous MD Sr. SPECT brain imaging in cerebrovascular disease. In: Nuclear medicine in clinical diagnosis and treatment (Murray IPC, Ell PJ, eds), Ed 2, pp 631-649. London: Churchill-Livingstone, 1998.

6. Brooks DJ. Positron emission tomography and single-photon emission computed tomography in central nervous system drug development. NeuroRx 2:226-236, 2005.

7. Eckert T, Eidelberg D. Neuroimaging and therapeutics in movement disorders. NeuroRx 2:361-371, 2005.

8. Heinz A, Jones DW, Raedler T, Coppola R, Knable MB, Weinberger DR. Neuropharmacological studies with SPECT in neuropsychiatric disorders. Nucl Med Biol 27:677-682, 2000

9. Dickerson BC, Sperling RA. Neuroimaging biomarkers for clinical trials of disease-modifying therapies in Alzheimer's disease. $\mathrm{Neu}$ roRx 2:348-360, 2005.

10. Bammer R, Skare S, Newbould R, Liu C, Thijs V, Ropele S, Clayton DB, Krueger G, Moseley ME, Glover GH. Foundations of advanced magnetic resonance imaging. NeuroRx 2:167-196, 2005.

11. Kuzniecky RI. Neuroimaging of epilepsy: therapeutic implications. NeuroRx 2:384-393, 2005.

12. Devous MD Sr. SPECT functional brain imaging. Instrumentation, radiopharmaceuticals and technical factors. In: Cerebral SPECT imaging (Van Heertum RL, Tikofsky RS, eds), Ed 3, pp 1-22. Philadelphia: Lippincott, Williams and Wilkins, 2000.

13. Bakshi R, Minagar A, Jaisani Z, Wolinsky JS. Imaging of multiple sclerosis: role in neurotherapeutics. NeuroRx 2:277-303, 2005.

14. Pirko I, Fricke ST, Johnson AJ, Rodriguez M, Macura SI. Magnetic resonance imaging, microscopy, and spectroscopy of the central nervous system in experimental animals. NeuroRx 2:250264, 2005.

15. Smith AP, Genna S. Imaging characteristics of ASPECT, a singlecrystal ring camera for dedicated brain SPECT. J Nucl Med 30: 796, 1989.

16. Hill TC, Stoddart HF, Doherty MD, Alpert NM, Wolfe AP. Simultaneous SPECT acquisition of CBF and metabolism. $J$ Nucl Med 29:876, 1988.

17. Devous MD Sr, Bonte FJ. Initial evaluation of cerebral blood flow imaging with a high-resolution, high-sensitivity three-headed SPECT system (PRISM). J Nucl Med 29:912, 1988.

18. Devous MD Sr, Gong W, Payne JK, Harris TS. Dynamic quantitative Xe-133 rCBF SPECT on the PRISM 3-headed tomograph: human studies. J Nucl Med 34:68P, 1993

19. Friston KJ, Worsley KJ, Frackowiak RSJ, Mazziotta JC, Evans AC. Assessing the significance of focal activations using their spatial extent. Hum Brain Map/I 1:210-220, 1994.

20. Talairach J, Tournoux P. Co-planar stereotaxic atlas of the human brain. Stuttgart: George Thieme Verlag, 1988.

21. Devous MD Sr, Payne JK, Lowe JL. Dual-isotope brain SPECT imaging with ${ }^{99 \mathrm{~m}} \mathrm{Tc}$ and ${ }^{123} \mathrm{I}$. Clinical validation using ${ }^{133} \mathrm{Xe}$ SPECT. J Nucl Med 33:1919-1924, 1992.

22. Stokely EM, Sveinsdottir E, Lassen NA, Rommer P. A single photon dynamic computer assisted tomograph (DCAT) for imaging brain function in multiple cross-sections. J Comput Assist Tomogr 4:230-240, 1980.

23. Winchell HS, Baldwin RM, Lin TH. Development of ${ }^{123}$ I-labeled amines for brain studies: localization of ${ }^{123} \mathrm{I}$ iodophenylalkylamines in rat brain. J Nucl Med 21:940-946, 1980.

24. Kung HF, Tramposh K, Blau M. A new brain imaging agent: $\left(I^{123}\right)$ HIPDM: N,N,N'-trimethyl-N'-(2-hydroxy-3-methyl-5-iodobenzyl) -1,3-propanediamine. J Nucl Med 24:66-72, 1983.

25. Neirinckx RD, Canning LR, Piper IM, et al. Technetium- $99 \mathrm{~m}$ d,1-HM-PAO: a new radiopharmaceutical for SPECT imaging of regional cerebral blood perfusion. J Nucl Med 28:191-202, 1987.

26. Volkert WA, Hoffman TJ, Seger RM, Trounter DE, Holmes RA. $\mathrm{Tc}^{99 \mathrm{~m}}$-propylene amine oxime $\left(\mathrm{Tc}^{99 \mathrm{~m}}-\mathrm{PnAO}\right)$; a potential brain radiopharmaceutical. Eur J Nuc Med 9:511-516, 1984.

27. Kung HF, Guo YH, Yu C-C, Billings J, Subramanyam V, Calabrese J. New brain perfusion imaging agents based on ${ }^{99 \mathrm{~m}} \mathrm{Tc}-$ bis(aminoethanethiol) complexes: stereoisomers and biodistribution. J Med Chem 32:437-444, 1989.

28. Leveille J, Demonceau G, De Roo M, Rigo P, Taillefer R, Morgan RA, et al. Characterization of Technetium-99m-1,1-ECD for brain perfusion imaging, part 2: biodistribution and brain imaging in humans. J Nucl Med 30:1902-1910, 1989.

29. Devous MD Sr, Payne JK, Lowe JL. Comparison of ${ }^{99 \mathrm{~m}} \mathrm{Tc}-\mathrm{ECD}$ to ${ }^{133} \mathrm{Xe}$ SPECT in normal controls and in patients with mild to moderate rCBF abnormalities. J Nucl Med 34:754-761, 1993.

30. Payne JK, Trivedi MH, Devous MD Sr. Comparison of $99 \mathrm{mTc}$ HM-PAO to 133Xe for the measurement of regional cerebral blood flow by SPECT. $J$ Nucl Med 37:1735-1740, 1996.

31. Kung HF, Kim HJ, Kung MP, Meegalla SK, Ploss1 K, Lee HF. Imaging of dopamine transporters in humans with technetium- $99 \mathrm{~m}$ TRODAT-1. Eur J Nucl Med 23:1527-1530, 1996.

32. Verhoeff NPLG. Radiotracer imaging of dopaminergic transmission in neuropsychiatric disorders. Psychopharmacology 147:217249, 1999.

33. Ichise M, Meyer JH, Yonekura Y. An introduction to PET and SPECT neuroreceptor quantification models. J Nucl Med 42:755763, 2001.

34. Schwartz RB, Carvalho PA, Alexander E III, Loeffler JS, Folkerth R, Holman BL. Radiation necrosis vs high-grade recurrent glioma: differentiation by using dual-isotope SPECT with ${ }^{201} \mathrm{Tl}$ and ${ }_{99 \mathrm{~m}}$ TC-HMPAO. Am J Neuroradiol 12:1187-1192, 1991.

35. Kaplan WD, Takvorian T, Morris JH, Rumbaugh CL, Connolly 
BT, Atkins HL. Thallium-201 brain tumor imaging: a comparative study with pathological correlation. J Nucl Med 28:47-52, 1987.

36. Baron GC, Lebrun-Grandie P, Collard P, Crouzel C, Mestelan G, Bousser MG. Noninvasive measurement of blood flow, oxygen consumption and glucose utilization in the same brain regions in man by positron emission tomography. J Nucl Med 23:391-399, 1982.

37. Phelps ME, Kuhl DE, Mazziotta JC. Metabolic mapping of the brain's response to visual stimulation: Studies in humans. Science 211:1445-1448, 1981.

38. Raichle ME, Grubb RL, Gado MH, Eichling JO, Ter-Pogossian MM. Correlation between regional cerebral blood flow and oxidative metabolism. Arch Neurol 33:523-526, 1976.

39. Roland PE, Eriksson L, Stone-Elander S, Widen L. Does mental activity change the oxidative metabolism of the brain? J Neurosci 7:2373-2389, 1987.

40. Devous MD Sr, Stokely EM, Chehabi HH, Bonte FJ. Normal distribution of regional cerebral blood flow measured by dynamic single-photon emission tomography. J Cereb Blood Flow Metab 6:95-104, 1986.

41. Gur RC, Gur RE, Obrist WD, Skolnick BE, Reivich M. Age and regional cerebral blood flow at rest and during cognitive activity. Arch Gen Psychiatry 44:617-621, 1987.

42. Hagstadius S, Risberg J Regional cerebral blood flow characteristics and variations with age in resting normal subjects. Brain Cogn 10:28-43, 1989.

43. Kuhl DE, Metter EJ, Riege WH, Phelps ME. Effects of human aging on patterns of local cerebral glucose utilization determined by the ${ }^{18} \mathrm{~F}$ fluorodeoxyglucose method. J Cereb Blood Flow Metab 2:163-171, 1982.

44. Baxter LR, Mazziotta JC, Phelps ME, Selin CE, Guze BH, Fairbanks L. Cerebral glucose metabolic rates in normal human females vs. normal males. Psychiatry Res 21:237-245, 1987.

45. Daniel DG, Mathew RJ, Wilson WH. Sex roles and regional cerebral blood flow. Psychiatry Res 27:55-64, 1988.

46. Devous MD Sr, Altuna D, Furl N, Gabbert G, Ngai WT, Cooper $\mathrm{W}$, et al. The functional neuroanatomy of speech and language development in pediatric normal controls. J Nucl Med 42:146P, 2001.

47. Bonte FJ, Devous MD Sr, Reisch JS. The effect of acetazolamide on regional cerebral blood flow in normal human subjects as measured by single photon emission computed tomography. Invest Radiol 23:564-568, 1988.

48. Rogg J, Rutigliano M, Yonas H, Johnson DW, Pentheny S, Latchaw RE. The acetazolamide challenge: imaging techniques designed to evaluate cerebral blood flow reserve. Am J Neuroradiol 110:803-810, 1989.

49. Mathew RJ, Barr DL, Weinman ML. Caffeine and cerebral blood flow. Br J Psychiat 143:604-608, 1983.

50. Petersen SE, Fox PT, Posner MI, Mintun M, Raichle ME. Positron emission tomographic studies of the cortical anatomy of singleword processing. Nature 331:585-589, 1988.

51. Roland PS, Tobey EA, Devous MD Sr. Pre-operative functional assessment of auditory cortex in adult cochlear implant users. Laryngoscope 111:77-83, 2001.

52. Procedure guidelines manual. Reston, VA: Society of Nuclear Medicine, pp 105-110, 1999.

53. Bond VP, Wielopolski L, Shani G. Current misinterpretations of the linear no-threshold hypothesis. Health Phys 70:877-882, 1996.

54. Fry RJ, Grosovsky A, Hanawalt PC, Jostes RF, Little JB, Morgan WF, et al. The impact of biology on risk assessment-workshop of the National Research Council's Board on Radiation Effects Research. July 21-22, 1997, National Academy of Sciences, Washington, DC. Rad Res 150:695-705, 1998.
55. Little MP, Muirhead CR. Curvature in the cancer mortality dose response in Japanese atomic bomb survivors: absence of evidence of threshold. Int J Rad Biol 74:471-480, 1998.

56. Pollycove M. Nonlinearity of radiation health effects. Environ Health Perspect 106:[Suppl 1]:363-368, 1998.

57. Mossman KL, Goldman M, Masse F, Mills WA, Schlager KJ, Vetter RJ. Radiation risk in perspective. Health Physics Society Position Statement. Health Phys Socy Newsl 24:2-3, 1996.

58. Ernst M, Freed ME, Zametkin AJ. Health hazards of radiation exposure in the context of brain imaging research: special consideration for children. J Nucl Med 39:689-698, 1998.

59. Pollycove M. The issue of the decade: hormesis. Eur J Nucl Med 22:399-401, 1995.

60. Paroo Z, Corey DR. Imaging gene expression using oligonucleotides and peptide nucleic acids. J Cell Biochem 90:437-442, 2003.

61. Massoud TF1, Gambhir SS. Molecular imaging in living subjects: seeing fundamental biological processes in a new light. Genes Dev 17:545-580, 2003.

62. Doubrovin M, Ponomarev V, Serganova I, Soghomonian T, Mayagawa T, Beresten T, et al. 2001. Development of a new reporter gene system-dsRed/xanthine phosphoribosyltranserase-Xanthine for molecular imaging of processes behind the intact blood-brain barrier. Mol Imaging 2:93-112, 2003.

63. Acton PD, Kung HF. Small animal imaging with high resolution single photon emission tomography. Nucl Med Biol 30:889-895, 2003.

64. Green MV, Seidel J, Vaquero JJ, Jagoda E, Lee I, Eckelman WC. High resolution PET, SPECT and projection imaging in small animals. Comput Med Imaging Graph 25:79-86, 2001.

65. Chatziioannou AF, Cherry SR, Shao Y, Silverman RW, Meadors K, Farquhar TH, et al. Performance evaluation of microPET: a high resolution lutetium oxyorthosilicate PET scanner for animal imaging. J Nucl Med 40:1164-1175, 1999.

66. Schramm NU, Ebel G, Engeland U, Schurrat T, Béhé M, Behr TM. High-resolution SPECT using multipinhole collimation. IEEE Trans Nucl Sci 50:315-320, 2003.

67. Beekman FJ, McElroy DP, Berger F, Gambhir SS, Hoffman EJ, Cherry SR. Towards in vivo nuclear microscopy: iodine- $125 \mathrm{im}-$ aging in mice using micro-pinholes. Eur J Nucl Med Mol Imaging 29:933-938, 2002.

68. Acton PD, Choi SR, Ploessl K, Kung HF. Quantification of dopamine transporter in mouse brain using ultra-high resolution single photon emission tomography. Eur J Nucl Med 29:691-698, 2002.

69. Min JJ, Gambhir SS. Gene therapy progress and prospects: noninvasive imaging of gene therapy in living subjects. Gene Ther 11:115-125, 2004.

70. Tavitian B. In vivo imaging with oligonucleotides for diagnosis and drug development. Gut 52[Suppl IV]:iv40-iv47, 2003.

71. Younes CK, Boisgard R, Tavitian B. Labelled oligonucleotides as radiopharmaceuticals: pitfalls, problems and perspectives. Curr Pharm Des 8:1451-1466, 2002.

72. Weissleder, R. Scaling down imaging: molecular mapping of cancer in mice. Nat Rev Cancer 2:11-18, 2002.

73. Rudin M, Weissleder R. Molecular imaging in drug discovery and development. Nat Rev Drug Disc 2:123-131, 2003.

74. Talbot PS, Laruelle M. The role of in vivo molecular imaging with PET and SPECT in the elucidation of psychiatric drug action and new drug development. Eur Neuropsychopharm 12:503-511, 2002.

75. Dougherty DD, Alpert NM, Rauch SL, Fischman AJ. In vivo neuroreceptor imaging techniques in psychiatric drug development. In: Psychiatric neuroimaging research: contemporary strategies (Rauch SL, ed), pp 193-205. Washington, DC: American Psychiatric Publishing, 2001. 